\title{
Effects of MATAS Hopscotch Technique in the Teaching of Fractions and Error Patterns Made by Year 5 Pupils
}

\author{
Devaki Periasamy, Kamariah Abu Bakar, and Ahmad Fauzi Mohd Ayub \\ Institute for Mathematical Research, University Putra Malaysia, 43400 Serdang, Selangor, Malaysia \\ Correspondence should be addressed to Devaki Periasamy; devaki.periasamy@yahoo.com
}

Received 29 May 2014; Revised 30 July 2014; Accepted 30 July 2014; Published 23 September 2014

Academic Editor: Gwo-Jen Hwang

Copyright (C) 2014 Devaki Periasamy et al. This is an open access article distributed under the Creative Commons Attribution License, which permits unrestricted use, distribution, and reproduction in any medium, provided the original work is properly cited.

\begin{abstract}
MATAS Hopscotch technique was created to solve the subtraction of three types of fractions. The study involved 56 pupils from two Year 5 classes. A quasi-experimental, nonrandomized control group, pretest-posttest delayed post-test was conducted on two intact groups, randomly assigned into control and experimental groups. A pretest was administered at the early stage of this study. The study described types of error made by the pupils in solving the subtraction of fractions. Rubrics, Hodes and Notling (1998), were used to describe types of error made by the pupils in the pretest and posttest. The findings in the pretest showed both groups made concept, directions, and careless errors. However, in the posttest, the experimental group made careless errors while the control group made concept, directions, and careless errors. The number of errors made by the control group was higher than that made by the experimental group.
\end{abstract}

\section{Background of Study}

Fractions are among the most difficult topics for students to learn [1-3]. In Malaysia, pupils have also been identified as having difficulties with fractions and this has perpetuated to secondary schools [4-8]. Low ability pupils found fractions to be more difficult than decimals or whole numbers [9]. They tended to use rule-based learning more often than high ability pupils. Furthermore, low ability pupils relied on standard written algorithms more than reflecting on number sense based methods. Errors due to whole number concept are dominant among the primary pupils and even secondary students $[4,5,10]$.

Fractions were viewed as part-wholes, subsets, ratios, quotients, and rational numbers [11]. Meanwhile, whole number knowledge represents numbers discretely and may therefore interfere with children's construction of the concept of fraction and rational numbers that are continuous [12]. Solving whole number problems through a mental model requires only the mental movement of items into or out of a space [13]. In contrast, the fraction problems would require not only these movements, but also rotation, separation, and recombination of various amounts.
Disjointed understanding of fraction concepts and operations caused students' errors [1]. Research has shown that errors in fractions made by primary pupils and secondary students were due to comprehension $[8,14]$. These difficulties stemmed from students' lack of formal knowledge and rote memorization of the algorithms [15].

Many strategies could be used to overcome these difficulties. One of them is the mnemonic strategies which have been successful in teaching mathematics [16]. The word mnemonic comes from the Greek word mnemonikos, meaning "relating to memory" [17]. A mnemonic is a ditty, rhyme, or word based on the initial letters of a list of items, often where the order of the items is crucial, used as an aid to memory. These strategies enhance student learning and memory by explicitly connecting new information with prior knowledge by means of visual and acoustic cues [18]. Mnemonic strategies are commonly divided into imagery illustrations, such as pictures or diagrams, and word-based devices, using words to aid memory [19]. It is considered though more effective to integrate imagery illustration and word-based devices as opposed to using them separately [20]. Mnemonic strategies can enhance students' abilities 
to encode and recall factual information, thereby improving their performance in classroom and standardized tests [18]. Mnemonics called "LAP fractions" developed by [21] improved the students' performances in solving fractions. However, only two studies reported that mnemonic strategies were utilised in teaching addition and subtraction of fractions $[21,22]$. Respondents for both studies were students with disabilities. Students using keyword mnemonics recalled more concrete than abstract words both immediately after learning and after a one-day time interval [23]. Research has shown that mnemonics have the potential to assist the learning process and improve formal reasoning [24]. Students who have difficulties with mathematics often benefit from mnemonic learning strategies which provide a step-by-step process to accomplish a task [25]. It is a tool that helps students to remember information [26].

Hence the need to remedy the pupils in learning fraction is necessary before the problems perpetuate to secondary schools. Based on the success reports on mnemonic strategies in literatures and the lack of research on techniques in teaching fractions, this study employs the mnemonic technique called the "MATAS Hopscotch" technique in the teaching and learning of fractions among Year 5 pupils.

Pupils' interest in learning fractions needs to be inculcated early. Instructions using mnemonic devices will help in improving pupils' understanding in learning fractions. The strategies will have positive impact on the pupils' learning of fractions and increase their self-confidence. It is important to know that teaching tools would raise pupils' understanding and mnemonics help them to remember better.

An analysis of types of error found in solving the subtraction of fractions before and after the implementation of "MATAS Hopscotch" technique will lead to a better understanding of this topic. The findings from this study should be given serious attention for the strategies will help mathematics teachers in particular in improving their teaching in fractions. The findings will also give teachers an alternative technique in teaching to improve students' performances in fractions. Additionally, the instrument used in this study can be beneficial to teachers to diagnose their pupils' errors in the subtraction of fractions. Utilising the MATAS Hopscotch technique will also help teachers to determine specific remedial steps for the pupils.

Research Questions. The research questions for this study are as follows.

(1) What types of error are made by the control and experimental groups in solving the subtraction of fractions in the pre- and posttests?

(2) What types of errors are made by the average and low ability pupils in the control and experimental group in solving the subtraction of fractions in the pre- and posttests?

\section{Methodology}

This study employed the quasi-experimental, nonrandomized control group, pretest-posttest delayed posttest design.
TABle 1: Pupils' abilities in control and experimental groups.

\begin{tabular}{lcc}
\hline Pupils' abilities & Control group & Experimental group \\
\hline Average & 13 & 10 \\
Low & 15 & 18 \\
\hline Total & 28 & 28 \\
\hline
\end{tabular}

Table 1 illustrated the pupils' abilities in the control and experimental groups. The distribution in Table 1 shows that there are a total of 28 pupils in each group. In the control group, out of 28 pupils, 13 are from average ability group while 15 are from low ability group. In the experimental group, out of 28 pupils, 10 are from the average ability group while 18 are from the low ability group.

In the Malaysian schools, there is a grading system which is used to categorize the pupils according to their ability. The pupils in the sample were grouped into 2 different ability groupings. The division was based on their scores for the mathematics paper during the final year examination in Year four. The pupils with scores between 60 and 79 were classified as of "average ability." Those with scores less than 59 were classified as "low ability." No one scored above $80 \%$.

Two similar lesson plans were prepared for the different teaching methods for the experimental and control groups. The instruments for the pretest and posttest consisted of 18 questions. Content analysis was conducted on the pretest and posttest. Rubrics [27] were utilised to identify types of errors made by the pupils.

The pretest was to measure the pupils' performance before the treatment while the posttest was to measure the pupils' performance after 4 weeks of the treatment. The pre- and posttest were also used to describe types of error made by the pupils. Examples of questions and answers were given.

\section{Sample Question}

Example 1. Consider

$$
\begin{aligned}
9 \frac{1}{6} & -3 \frac{5}{6} \\
& =8 \frac{7}{6}-3 \frac{5}{6}=5 \frac{2}{6}=5 \frac{1}{3} \text { (Correct) } \\
& =9 \frac{1}{6}-3 \frac{5}{6}=6 \frac{4}{6} \text { (Incorrect) }
\end{aligned}
$$

Based on Example 1 above, the correct answer at the end was given 1 mark and no mark was allocated for incorrect answer.

A rubric is a device used to interpret data gathered from pupils' performances. More precisely, it is a guide to differentiate types of errors made based on the pupils' performances. Hodes and Notling [27] proposed four types of errors. The errors were concept errors, directions error, application errors, and careless errors. They stated that concept errors referred to mistakes made when the learner does not understand the properties or principles covered in the textbook and lecture while directions errors occurred when learners skip directions or misunderstand directions 
but answer the question or the problem anyway. Meanwhile, application errors referred to errors made when they know the concept but cannot apply it to a specific situation or question while careless errors referred to errors made which can be caught automatically upon reviewing one's own work. Thus, in this study, the rubrics were adopted and adapted to identify each pupil's performance in terms of types of error made by them.

In this study, concept errors referred to errors due to whole numbers concept while pupils' errors due to subtracting from right to left were identified as directions errors. Application errors occurred when the pupils know the concept but are unable to apply the concept correctly. Careless errors referred to when the pupils are able to apply the concept but they did not simplify the end product or subtracted incorrectly to obtain the end product. In this study, no errors were added when the pupils did not make any errors.

\subsection{Examples of Identifying Types of Errors}

Example 2. Consider

$$
\begin{aligned}
9 \frac{1}{6} & -3 \frac{5}{6} \\
& =8 \frac{11}{6}-3 \frac{5}{6} \text { (Concept errors) } \\
& =5 \frac{6}{6} .
\end{aligned}
$$

Example 3. Consider

$$
\begin{aligned}
9 \frac{1}{6} & -3 \frac{5}{6} \\
& =8 \frac{11}{6}-3 \frac{5}{6} \text { (Concept errors) } \\
& =5 \frac{5}{6} .
\end{aligned}
$$

Example 4. Consider

$$
\begin{aligned}
9 \frac{1}{6} & -3 \frac{5}{6} \\
& =8 \frac{11}{6}-3 \frac{5}{6} \text { (Concept errors) } \\
& =4 \frac{6}{6} .
\end{aligned}
$$

Based on Examples 2, 3, and 4 given above, the pupil used the whole numbers concept to solve the problem. These were classified as concept errors.
Example 5. Consider

$$
\begin{aligned}
9 \frac{1}{6} & -3 \frac{5}{6} \\
& =6 \frac{5}{6}-\frac{1}{6} \text { (Directions errors) } \\
& =6 \frac{4}{6} .
\end{aligned}
$$

Example 6. Consider

$$
\begin{aligned}
9 \frac{1}{6} & -3 \frac{5}{6} \\
& =9 \frac{5}{6}-3 \frac{1}{6} \text { (Directions errors) } \\
& =6 \frac{4}{6} .
\end{aligned}
$$

The errors made in Examples 5 and 6 given were subtracting from right to left. Thus, the errors made by the pupil were classified as directions errors.

Example 7. Consider

$$
\begin{aligned}
9 \frac{1}{6} & -3 \frac{5}{6} \\
& =8 \frac{1 \times 6}{6}-3 \frac{5}{6} \text { (Application errors) } \\
& =8 \frac{6}{6}-3 \frac{5}{6} \\
& =5 \frac{1}{6} .
\end{aligned}
$$

In Example 7 given, the pupil knew the concept but the pupil applied the concept incorrectly. Thus, these types of error were classified as application errors.

Example 8. Consider

$$
\begin{aligned}
9 \frac{1}{6} & -3 \frac{5}{6} \\
& =8 \frac{7}{6}-3 \frac{5}{6} \\
& =5 \frac{2}{6} \text { (Careless error). }
\end{aligned}
$$

Example 9. Consider

$$
\begin{aligned}
9 \frac{1}{6} & -3 \frac{5}{6} \\
& =8 \frac{7}{6}-3 \frac{5}{6} \\
& =5 \frac{3}{6} \text { (Careless errors) } \\
& =5 \frac{1}{2} .
\end{aligned}
$$


Based on Examples 8 and 9 given above, the pupil knew the concept but the pupil made errors by leaving the end product without simplifying the fraction. In the second example, the pupil subtracted the numerator incorrectly. Thus these types of errors were classified as careless error.

Example 10. Consider

$$
\begin{aligned}
9 \frac{1}{6} & -3 \frac{5}{6} \\
& =8 \frac{7}{6}-3 \frac{5}{6} \\
& =5 \frac{2}{6} \\
& =5 \frac{1}{3} \text { (No errors). }
\end{aligned}
$$

In Example 10 above, the correct solution was given; thus these were classified as no errors.

2.2. Examples of Identifying Number of Pupils Made Errors. In this study, 28 pupils were involved. Number of pupils that answered all the questions correctly in the subtraction of fractions was classified as no errors. If the pupils made errors subtraction of fractions, then types of error made by pupils were identified as shown in Table 2.

Finally, the total number of pupils made those types of error was calculated as shown in Table 3.

MATAS was presented using the idea of playing hopscotch. Hopscotch is a children's game that can be played with several players or alone. Hopscotch is a popular playground game in which players toss a small object into numbered spaces of a pattern of rectangles outlined on the ground and then hop or jump through the spaces to retrieve the object. There are many types of hopscotch. The image of hopscotch is shown in Figure 1.

The diagram of hopscotch was adopted and adapted. The numbered spaces were changed. A new hopscotch called MATAS Hopscotch was developed. MATAS was written in vertical form in the adapted hopscotch. Five-step mnemonic, called MATAS, was developed for teaching subtraction of fractions as shown in Table 4.

MATAS Hopscotch was used to solve subtraction of fractions. MATAS Hopscotch was as shown in Figure 2.

Six rows were prepared. The second row, third row, and the fourth row were divided into two. MATAS was written on the left as shown In Figure 2. Subtraction of fractions was written in the first row as shown below:

$$
3 \frac{2}{7}-\frac{5}{7}=
$$

The left fraction moves down to the left and the right fraction moves down to the right. The letter " $M$ " showed that the pupils need to subtract 1 from the whole number while the fraction on the right remains unchanged as shown below:

\begin{tabular}{|l|l|}
\hline \multicolumn{2}{|c|}{9} \\
\hline 7 & 8 \\
\hline \multicolumn{2}{|c|}{6} \\
\hline 4 & 5 \\
\hline \multicolumn{2}{|c|}{3} \\
\hline 1 & 2 \\
\hline
\end{tabular}

FIGURE 1

TABLE 2

\begin{tabular}{ll}
\hline $\begin{array}{l}\text { Number of } \\
\text { pupils }\end{array}$ & Types of error made in the subtraction of fractions \\
\hline Pupil 1 & No error \\
Pupil 2 & Concept errors and directions error \\
Pupil 3 & Concept errors and directions errors \\
Pupil 4 & Directions errors \\
\hline
\end{tabular}

TABLE 3

\begin{tabular}{lc}
\hline Type of errors & Subtraction of fractions \\
\hline Concept errors & 2 \\
Directions errors & 3 \\
Application errors & - \\
Careless errors & - \\
No errors & 1 \\
\hline
\end{tabular}

TABLE 4: The mnemonic step-MATAS.

\begin{tabular}{ll}
\hline $\mathrm{M}$ & Minus 1 from the whole number \\
$\mathrm{A}$ & Add $(1 / 1)$ \\
$\mathrm{T}$ & Take $(1 / 1)$ and multiply with $(d / d)$ \\
$\mathrm{A}$ & (d: denominator) \\
$\mathrm{S}$ & Add and write it in the last row \\
\hline
\end{tabular}

\begin{tabular}{|lr|r|}
\hline \multicolumn{3}{|c|}{$\downarrow^{2} \downarrow^{\frac{2}{7}-\frac{5}{7}}=$} \\
\hline M $\quad 3-1 \frac{2}{7}$ & & $-\frac{5}{7}$ \\
\hline
\end{tabular}

Once the pupils completed the first task, they move to the next step where the letter "A" was written. The pupils need to add $1 / 1$ while the fraction on the right remains unchanged:

\begin{tabular}{|r|r|}
\hline A $\quad 2 \frac{2}{7}+\frac{1}{1}$ & $-\frac{5}{7}$ \\
\hline
\end{tabular}




\begin{tabular}{|l|l|}
\hline \multicolumn{2}{|l|}{} \\
\hline M & \\
\hline A & \\
\hline T & \\
\hline A & \\
\hline S & \\
\hline
\end{tabular}

Figure 2

Next they move to the third step where the letter " $T$ " was written. The pupils need to take $1 / 1$ and multiply with $d / d$ while the fraction on the right remains unchanged:

$$
\begin{array}{|l|r|}
\hline \mathrm{T} \quad 2 \frac{2}{7}+\frac{1}{1} \times \frac{7}{7} & -\frac{5}{7} \\
\hline
\end{array}
$$

After that, the pupils proceed to the next step where the letter "A" was written. The pupils add and write the answer in the last row while the fraction on the right remains unchanged:

\begin{tabular}{|r|r|}
\hline A $\quad 2 \frac{2}{7}+\frac{7}{7}$ & $-\frac{5}{7}$ \\
\hline
\end{tabular}

Finally, they move to the last row where the letter "S" was written. The pupils solve and simplify the fraction problem:

\begin{tabular}{rl|}
\hline$S \quad 2 \frac{9}{7}-\frac{5}{7}$ \\
$=2 \frac{4}{7}$ \\
\hline
\end{tabular}

The purpose of this study is to identify types of errors made before and after the implementation of MATAS Hopscotch technique in solving the subtraction of the three types of mixed numbers. Type 1 is proper fractions subtracted from mixed number where the value of subtrahend is bigger than minuend, such as $3(2 / 7)-(5 / 7)$. Type 2 is mixed numbers subtracted from mixed numbers where the value of subtrahend is bigger than minuend, such as $9(1 / 3)-2(2 / 3)$. Type 3 is mixed numbers subtracted from whole numbers, such as $8-2(7 / 9)$. The focus is on the average and low ability pupils.

\section{Findings}

Table 5 showed the distribution of errors in the subtraction of fractions made by the control group and treatment group in the pretest by percentage. The results showed that 14 (50\%) pupils in the control group made concept errors compared to $13(46.4 \%)$ pupils in the treatment group in the pretest. The result indicated that $12(42.9 \%)$ average ability pupils and 2 (7.1\%) low ability pupils in the control group made concept errors compared to 10 (35.7\%) of average ability pupils and $3(10.7 \%)$ low ability pupils in the treatment group made concept errors in the pretest. Both groups made similar errors in the pretest.

A total of 27 (96.4\%) pupils in the control group made directions errors in the pretest compared to $26(92.9 \%)$ pupils in the treatment group. The results also showed that $12(42.9 \%)$ average ability and $15(53.6 \%)$ low ability pupils in the control group made directions errors compared to $8(28.6 \%)$ average ability and $18(64.3 \%)$ low ability pupils in the treatment group in the pretest. Average ability pupils in the control group made more directions compared to average ability pupils in the treatment group errors in the pretest. However, the low ability pupils in the treatment group made more directions errors compared low ability among the control group in the pretest.

The results showed that $1(3.6 \%)$ average ability pupil in the control group made careless errors compared to $2(7.1 \%)$ of them in the treatment group who made careless errors in the pretest. Low ability pupils in both groups made no careless errors in the pretest. The number of average ability pupils who made careless error is quite similar in both groups. This indicated that only a pupil in the control group and two pupils in the treatment group were able to apply the concept. However they did not simplify the end product or subtracted incorrectly to obtain the end product.

Table 6 showed the distribution of errors in the subtraction of fractions made by the control group and treatment group in the posttest by percentage. The results showed that only 7 (25\%) low ability pupils in the control group made concept errors compared to no concept errors made by the pupils in the treatment group in the pretest. The treatment group made no concept errors compared to the control group in the posttest. The concept errors made by the control group were less in the posttest compared to the pretest. Average ability pupils in the control group made no concept errors in the posttest compared to the pretest. Low ability pupils in the control group made less concept errors in the posttest compared to the pretest. The average ability and low ability pupils in the treatment group made no concept errors in the posttest compared to the pretest. This indicated that both groups showed improvement in the posttest. The average ability pupils in both groups made no concept errors in the posttest. Similar improvement was made by the average ability pupils in both groups in the posttest. However, the low ability pupils in the treatment showed more improvement than the low ability pupils in the control group in the posttest.

The results indicated that $4(14.3 \%)$ average ability pupils and $8(28.6 \%)$ low ability pupils in the control group made directions errors compared to no directions errors made by the pupils in the treatment group in the posttest. The numbers of directions errors made by the control group were less in the posttest compared to the pretest. The average ability pupils and low ability pupils in the control group made less directions errors in the posttest compared to the pretest. The average ability and low ability pupils in the treatment group made no directions errors in the posttest compared to pretest. This indicated that the treatment group showed more improvement compared to the control group in the posttest. 
TABLE 5: Distribution of errors in the subtraction of fractions made by the control group and treatment group in the pretest.

\begin{tabular}{|c|c|c|c|c|c|c|}
\hline \multirow{3}{*}{$\begin{array}{l}\text { Types } \\
\text { of errors }\end{array}$} & \multicolumn{6}{|c|}{ Pretest } \\
\hline & \multicolumn{3}{|c|}{ Control group } & \multicolumn{3}{|c|}{ Treatment group } \\
\hline & Average ability & Low ability & Total & Average ability & Low ability & Total \\
\hline $\begin{array}{l}\text { Whole number } \\
\text { concept errors }\end{array}$ & $12(42.9 \%)$ & $2(7.1 \%)$ & $14(50 \%)$ & $10(35.7 \%)$ & $3(10.7 \%)$ & $13(46.4 \%)$ \\
\hline Directions errors & $12(42.9 \%)$ & $15(53.6 \%)$ & $27(96.4 \%)$ & $8(28.6 \%)$ & $18(64.3 \%)$ & $26(92.9 \%)$ \\
\hline Application errors & - & - & - & - & - & - \\
\hline Careless errors & $1(3.6 \%)$ & - & $1(3.6 \%)$ & $2(7.1 \%)$ & - & $2(7.1 \%)$ \\
\hline No errors & - & - & - & - & & \\
\hline
\end{tabular}

TABLE 6: Distribution of errors in the subtraction of fractions made by the control group and treatment group in the posttest.

\begin{tabular}{|c|c|c|c|c|c|c|}
\hline \multirow{3}{*}{$\begin{array}{l}\text { Types } \\
\text { of errors }\end{array}$} & \multicolumn{6}{|c|}{ Posttest } \\
\hline & \multicolumn{3}{|c|}{ Control group } & \multicolumn{3}{|c|}{ Treatment group } \\
\hline & Average ability & Low ability & Total & Average ability & Low ability & Total \\
\hline Concept errors & - & $7(25 \%)$ & $7(25 \%)$ & - & - & - \\
\hline Directions errors & $4(14.3 \%)$ & $8(28.6 \%)$ & $12(42.9 \%)$ & - & - & - \\
\hline Application errors & - & - & - & - & - & - \\
\hline Careless errors & $13(46.4 \%)$ & $9(32.1 \%)$ & $22(78.6 \%)$ & $7(25 \%)$ & $15(53.6 \%)$ & $22(78.6 \%)$ \\
\hline No errors & & & & $3(10.7 \%)$ & $3(10.7 \%)$ & $6(21.4 \%)$ \\
\hline
\end{tabular}

The results also showed that $22(78.6 \%)$ pupils in the control and treatment groups made careless errors in the posttest. The result indicated that $13(46.4 \%)$ average ability pupils in the control group made careless errors compared to $7(25 \%)$ of them in the treatment group in the posttest. The result also indicated that $9(32.1 \%)$ low ability pupils in the control group made careless errors compared to 15 (53.6\%) of them in the treatment group in the posttest. This indicated that average ability pupils in the treatment group were able to give the answers in the simplest form correctly compared to the average ability pupils in the control group in the posttest. The low ability pupils in treatment made more careless errors compared to the low ability pupils in the control group. This showed that more low ability pupils in the treatment group improved in applying the concept.

The result showed that $3(10.7 \%)$ of average ability and low ability pupils in the treatment made no errors in the posttest compared to the control group. This also showed that the pupils in the treatment group answered all the questions correctly in the posttest. However, no one answered all the questions correctly in the control group in the posttest. This also indicated that the treatment group showed improvement in the posttest.

\section{Discussion and Suggestions}

This study is on the types of errors made by the average and low ability Year 5 pupils in the subtraction of fractions. It was carried out in two classes in a primary school in the state of Selangor, Malaysia. A quasi-experimental, nonrandomized control group, pretest-posttest and a delayed posttest, was utilised on two intact groups, randomly assigned into control and experimental groups.
The findings showed generally that both the control and treatment groups encountered difficulties in subtraction of fractions in the pretest. Most of them made directions errors. Procedural knowledge in fractions involved mathematical rules and routines. As [14] mentioned, pupils just did not comprehend these rules. The findings of this study also supported [15] who stated that students misapplied the basic rules in mathematics.

Both groups however showed improvement in the posttest. In particular, the treatment group showed drastic improvement in the subtraction of fractions compared to the control group in the posttest. With regard to the average and low ability pupils in the pretest, the average ability pupils did more concept errors compared to the low ability pupils who made more directions errors. The low ability pupils might not understand the basic mathematical rules and routines, but the situation where the average ability pupils made more concept errors (involving mathematical relationships) should be something to be concerned about. This finding seemed to support what [1] stated that students had disjointed understanding of fraction concepts and operations, the mathematical relationships. However, in this study, with the mnemonics strategies treatment, it was found that the average and low ability pupils made great improvement where they only made careless errors compared to the control group. Here, it can be deduced that the mnemonic strategies given to the treatment group did enhance memory especially in connecting new information with prior knowledge by means of visual and acoustic cues $[18,24]$. The strategies seemed to provide students with "a great way to remember" information [26]. The finding also supported what [20, 21] stated that imagery illustration and word-based devices were found to be effective in improving the students' performances. 
Therefore, perhaps teachers should familiarise themselves with mnemonic techniques for they are effective for both immediate and delayed recall and they can facilitate performance on tasks that go beyond simple rote recall. Similarly, this study found that the MATAS Hopscotch technique can reduce errors and improve students' performances in the solving of fractions. The technique helps reduce errors made by both ability group pupils, especially the low ability pupils in solving the subtraction of fractions. It is hoped that teachers will utilise the MATAS Hopscotch technique for it will improve pupils' performances in fractions. Furthermore, MATAS Hopscotch technique can be used in the classroom because it is easy for the students to remember. For future research, perhaps pupils' attitudes towards MATAS Hopscotch technique could be investigated. This can perhaps throw some light into the effectiveness of the technique.

\section{Conclusion}

Overall, it can be said that the average and low ability pupils found difficulties in the subtractions of fractions. The errors made were mainly concept and directions. The lack of comprehension in these two mathematical rules will perpetuate and accumulate if steps are not taken where fractions are introduced in the early years of schooling. Suitable teaching techniques should be introduced in the early years of learning fractions and the results of this study have proven that the MATAS Hopscotch technique can reduce errors in solving the subtraction of fractions among the Year 5 pupils.

\section{Conflict of Interests}

The authors declare that there is no conflict of interests regarding the publication of this paper.

\section{References}

[1] G. Brown and R. J. Quinn, "Algebra students' difficulty with fractions: an error analysis," The Australian Mathematics Teacher, vol. 62, no. 4, pp. 28-40, 2006.

[2] M. M. M. Mazzocco and K. T. Devlin, "Parts and "holes": gaps in rational number sense among children with vs. without mathematical learning disabilities," Developmental Science, vol. 11, no. 5, pp. 681-691, 2008.

[3] S. A. Hecht and K. J. Vagi, "Sources of group and individual differences in emerging fraction skills," Journal of Educational Psychology, vol. 102, no. 4, pp. 843-859, 2010.

[4] Malaysian Examination Panel, Kupasan Mutu Jawapan UPSR 2004, Ministry of Education, Kuala Lumpur, Malaysia, 2004.

[5] Malaysian Examination Panel, Kupasan Mutu Jawapan UPSR 2007, Ministry of Education Malaysia, Kuala Lumpur, Malaysia, 2007.

[6] T. Z. Tengku Zainal, R. Mustapha, and A. R. Habib, "Pedagogical content knowledge of mathematic teachers on fraction: a case study at primary schools," Jurnal Pendidikan Malaysia, vol. 34, no. 1, pp. 131-153, 2009.

[7] N. Noordin, F. Abdol Razak, R. Dollah, and R. Alias, "Identifying equivalent pictorial representation of a fraction \& a whole,"
Procedia-Social and Behavioral Sciences, vol. 42, pp. 106-116, 2010.

[8] N. Idris and L. M. Narayanan, "Error patterns in addition and subtraction of fractions among form two students," Journal of Mathematics Education, vol. 4, no. 2, pp. 35-54, 2011.

[9] T. Yee-Ling, "The number sense of preservice elementary school teachers," College Student Journal, vol. 39, no. 4, pp. 647-680, 2005.

[10] F. Abdol Razak, N. Noordin, R. Alias, and R. Dollah, "How do 13 year olds in Malaysia compare fractions?" Procedia-Social and Behavioral Sciences, vol. 42, pp. 106-116, 2010.

[11] M. L. Witherspoon, "Fractions: in search of meaning," Arithmetic Teacher, vol. 40, no. 8, pp. 482-485, 1993.

[12] Y. Ni and Y. Zhou, "Teaching and learning fraction and rational numbers: the origins and implications of whole number bias," Educational Psychologist, vol. 40, no. 1, pp. 27-52, 2005.

[13] K. S. Mix, S. C. Levine, and J. Huttenlocher, "Early fraction calculation ability," Developmental psychology, vol. 35, no. 1, pp. 164-174, 1999.

[14] I. H. Raduan, "Error analysis and the corresponding cognitive activities committed by year five primary students in solving mathematical word problems," Procedia-Social and Behavioral Sciences, vol. 2, no. 2, pp. 3836-3838, 2010.

[15] M. Isiksal and E. Cakiroglu, "The nature of prospective mathematics teachers' pedagogical content knowledge: the case of multiplication of fractions," Journal of Mathematics Teacher Education, vol. 14, no. 3, pp. 213-230, 2011.

[16] P. Maccini, C. A. Mulcahy, and M. G. Wilson, "a followup of mathematics interventions for secondary students with learning disabilities," Learning Disabilities Research Practice, vol. 22, no. 1, pp. 58-74, 2007.

[17] N. Hunt, "Using mnemonics in teaching statistics," Teaching Statistics, vol. 32, no. 3, pp. 73-75, 2010.

[18] M. A. Mastropieri and T. E. Scruggs, "Enhancing school success with mnemonic strategies," Intervention in School and Clinic, vol. 33, no. 4, pp. 201-208, 1998.

[19] R. N. Carney and J. R. Levin, "Do mnemonic memories fade as time goes by? Here's looking a new!'” Contemporary Educational Psychology, vol. 23, no. 3, pp. 276-297, 1998.

[20] D. Leutner, C. Leopold, and E. Sumfleth, "Cognitive load and science text comprehension: effects of drawing and mentally imagining text content," Computers in Human Behavior, vol. 25, no. 2, pp. 284-289, 2009.

[21] D. W. Test and M. F. Ellis, "The effects of LAP fractions on addition and subtraction of fractions with students with mild disabilities," Education and Treatment of Children, vol. 28, no. 1, pp. 11-24, 2005.

[22] L. M. Joseph and A. D. Hunter, "Differential application of a cue card strategy for solving fraction problems: exploring instructional utility of the cognitive assessment team," Child Study Journal, vol. 31, no. 2, pp. 123-136, 2001.

[23] S. de Graaff, L. Verhoeven, A. M. T. Bosman, and F. Hasselman, "Integrated pictorial mnemonics and stimulus fading: teaching kindergartners letter sounds," British Journal of Educational Psychology, vol. 77, no. 3, pp. 519-539, 2007.

[24] G. Laing, "An empirical test of mnemonic devices to improve learning in elementary accounting," Journal of Education for Business, vol. 85, no. 6, pp. 349-358, 2010. 
[25] M. W. Dunn, “ Illustrating story plans: does a mnemonic strategy including art media render more elaborate text?" Journal of Visual Literacy, vol. 31, no. 1, pp. 93-123, 2012.

[26] J. L. Fontana, T. Scruggs, and M. A. Mastropieri, "Mnemonic strategy instruction in inclusive secondary social studies classes," Remedial and Special Education, vol. 28, no. 6, pp. 345355, 2007.

[27] E. Hodes and P. Nolting, Winning at Mathematics? SBCC Mathematics Department, Academic Success Press, 1998. 

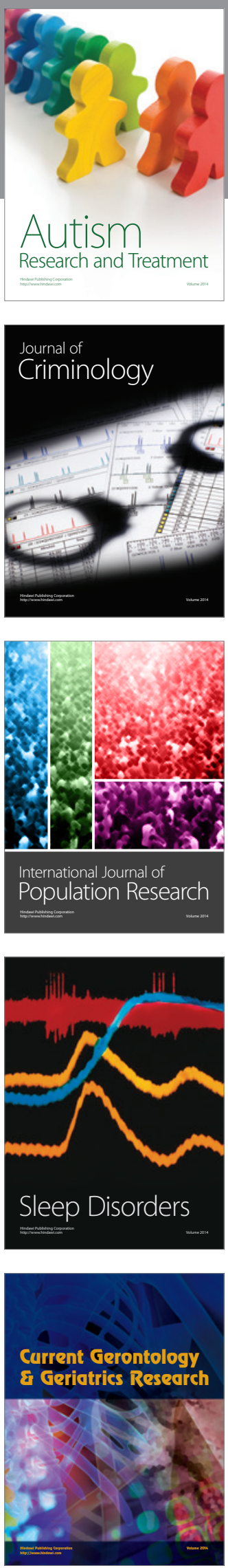
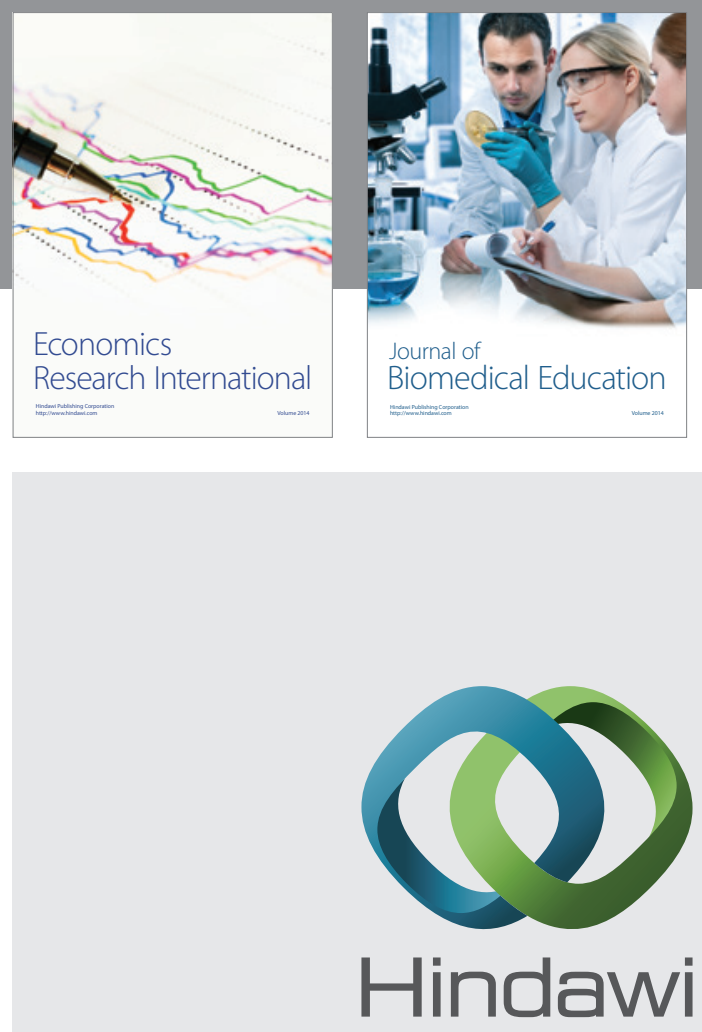

Submit your manuscripts at

http://www.hindawi.com
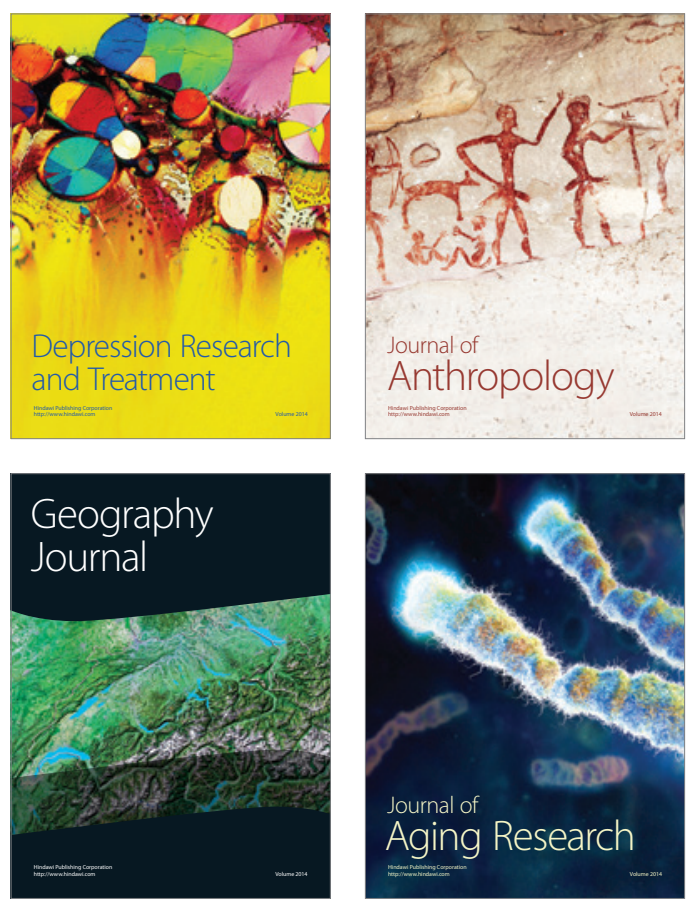
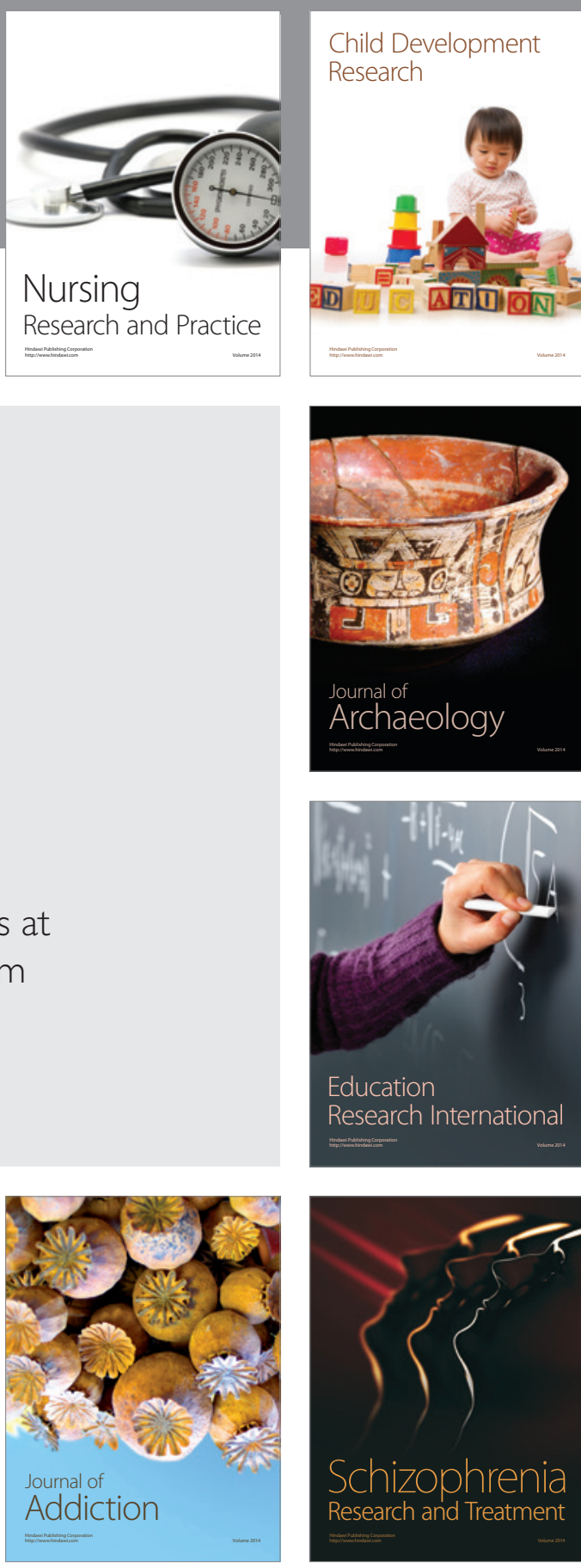

(D)
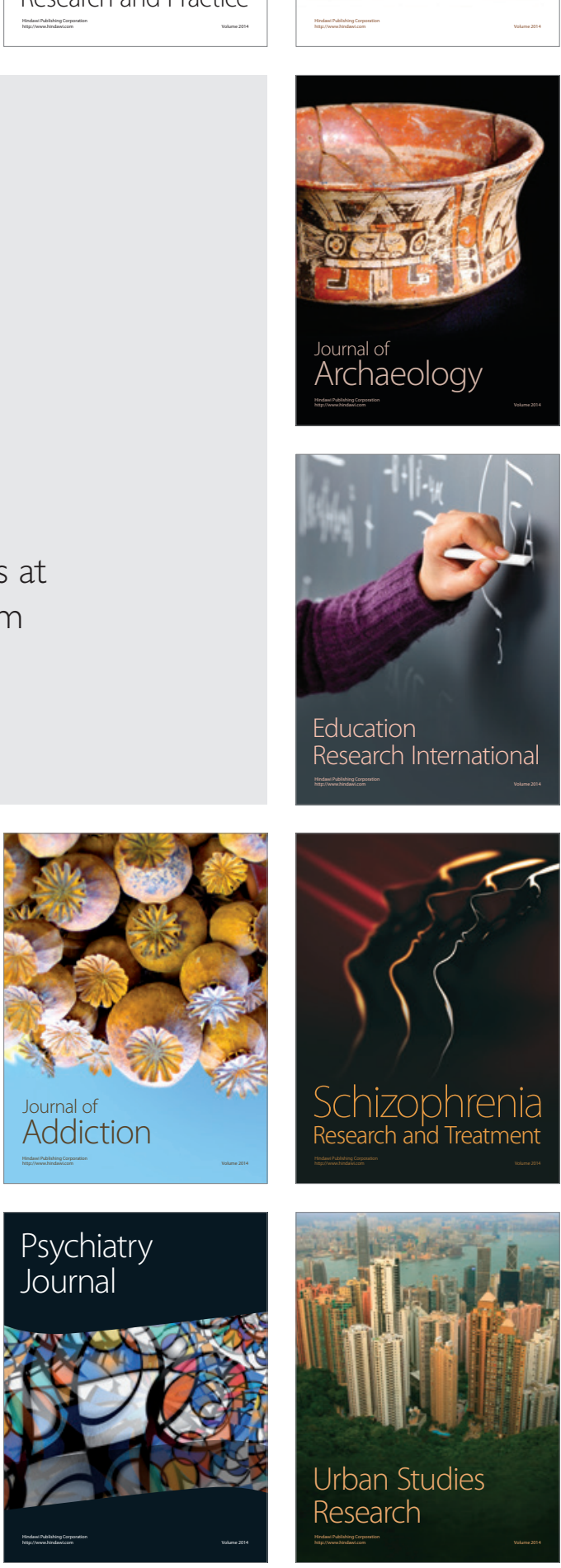